\title{
PTC simulations, stochastic optimization and safety strategies for groundwater pumping management: case study of the Hersonissos Coastal Aquifer in Crete
}

\author{
P. N. Stratis ${ }^{1}$ Z. A. Dokou ${ }^{2}$ - G. P. Karatzas ${ }^{2}$ E. P. Papadopoulou ${ }^{3}$. \\ Y. G. Saridakis ${ }^{1}$
}

Received: 18 September 2015/ Accepted: 30 May 2016/Published online: 16 June 2016

(c) The Author(s) 2016. This article is published with open access at Springerlink.com

\begin{abstract}
Recently, the well-known Princeton Transport Code (PTC), a groundwater flow and contaminant transport simulator, has been coupled with the ALgorithm of Pattern EXtraction (ALOPEX), a real-time stochastic optimization method, to provide a freshwater pumping management tool for coastal aquifers, aiming in preventing saltwater intrusion. In our previous work (Proceedings of INASE/CSCCWHH 2015, Recent Advances in Environmental and Earth Sciences and Economics, pp 329-334, 2015), the PTCALOPEX approach was used in studying the saltwater contamination problem for the coastal aquifer at Hersonissos, Crete. Extending these results, in the present study the PTC-ALOPEX approach is equipped with a nodal safety strategy that effectively controls saltwater front's advancement inside the aquifer. In cooperation with an appropriate penalty system, the performance of PTCALOPEX algorithm is studied considering several pumping and weather condition scenarios. This study also establishes pumping/well scenarios that ensure the needed volume of fresh water to the local community without risking saltwater contamination.
\end{abstract}

Y. G. Saridakis

y.saridakis@amcl.tuc.gr

1 School of Production Engineering and Management, Applied Math \& Computers Laboratory, Technical University of Crete, Crete, 73100 Chania, Greece

2 School of Environmental Engineering, Geoenvironmental Engineering Laboratory, Technical University of Crete, Crete, 73100 Chania, Greece

3 School of Mineral Resources Engineering, Applied Math \& Computers Laboratory, Technical University of Crete, Crete, 73100 Chania, Greece
Keywords ALOPEX stochastic optimization - PTC code · Coastal aquifers - Saltwater intrusion · Pumping management

\section{Introduction}

Saltwater Intrusion (SWI) in coastal aquifers poses a significant threat to the quality of groundwater reserves. SWI is mainly attributed to unrestrained freshwater withdrawals that disturb the natural freshwater-saltwater equilibrium in groundwater coastal systems. To protect groundwater reserves and design sustainable water management strategies for coastal aquifers, researchers have been intensively studying SWI via the combined use of mathematical models, numerical simulations and optimization algorithms (see for example Alimohammadi and AfsharUnit 2005; Ospina et al. 2006; Stratis et al. 2015; Strack 1989; Karterakis et al. 2007; Mantoglou 2003).

It is well known that the nonlinear behavior of unconfined coastal aquifers, pertaining to the response of the hydraulic head to the pumping conditions, results in nonlinear optimization. To circumvent this problem, earlier optimization formulations were based on modified versions of linear (Shamir et al. 1984; Uddameri and Kuchanur 2007 among others) or non-linear programming (Gorelick et al. 1984; Willis and Finney 1988; Reinelt 2005; Mantoglou et al. 2004). In the last two decades, there has been an increase in developing and applying heuristic and evolutionary algorithms for solving water-resources management problems, including SWI. The advantage of using these algorithms is that they can handle non differentiable and discontinuous functions, as well as integer variables, but at the expense of increased computational effort (Yeh 2015). Heuristic and evolutionary algorithms have been 
used with success in various implementations that deal with the SWI management problem (Cai et al. 2001; Karterakis et al. 2007; Mantoglou and Papantoniou 2008; Dhar and Datta 2009; Kourakos and Mantoglou 2011; Karatzas and Dokou 2015). Detailed information regarding simulation-optimization models and their application to coastal groundwater optimization may be found in the recent reviews of Sreekanth and Datta (2015) and Ketabchi and Ataie-Ashtiani (2015).

SWI is being modeled by two main simulation approaches: the Sharp Interface and Dispersive Interface (densitydependent) simulation models. Both approaches have distinct advantages and disadvantages in the context of developing simulation-optimization models for coastal aquifer management (Sreekanth and Datta 2015). For a detailed analysis of the theoretical developments and implementation of these two modeling approaches the interested reader is directed to Werner et al. (2013). In this work, the sharp interface approach was used. Thus, it is expected that the validity of the solutions obtained here are subject to the conditions imposed by the assumptions of the sharp interface combined with the Ghyben-Herzberg relationship. In general, the sharp interface model is suitable when the transition zone is narrow relative to the scale of the problem. This can be affected by many parameters. According to Llopis-Albert and Pulido-Velazquez (2014) the transition zone width remains relatively narrow for lower values of dispersion (longitudinal and transverse dispersivity) and hydrogeological parameters (transmissivity or horizontal hydraulic conductivity) and higher values of vertical hydraulic conductivity and recharge.

The objective of this work is to assess SWI intrusion for the Hersonissos aquifer, located in Crete, Greece, and provide, in the sequel, sustainable management alternatives. The SWI phenomenon at this aquifer has been studied previously by a number of researchers. In Papadopoulou et al. (2009) (see also Papadopoulou et al. 2010), the finite difference MODFLOW and the finite element PTC models are employed to simulate saltwater intrusion and compare the numerical results to the ones obtained by geostatistical techniques (Kriging). In Karterakis et al. (2007), the PTC simulator is coupled with a differential evolution (DE) algorithm to maximize the total extracted freshwater volume from five pre-selected pumping locations (production wells) while satisfying minimum hydraulic head constraints at specified locations, ensuring no further intrusion of seawater. The same approach was saken in Dokou and Karatzas (2012), using sequential linearization to reduce the computational cost. The Hersonissos aquifer has been also studied in Voudouris et al. (2004), by making use of geostatistical techniques (Kriging and Ordinary Kriging).
ALOPEX stochastic unconstrained optimization originates at the area of neurophysiology (cf. Harth and Tzanakou 1974) and, since then, has been applied with success in many real-time applications (see for example Zakynthinaki and Saridakis (2003), and the references therein). Recently, in Stratis et al. (2015), the dynamics of the algorithm were studied in depth for the problem of saltwater intrusion of coastal aquifers. The determination of the algorithm's feedback and noise amplitudes and the introduction of an effective penalty system, to enforce problem's constraints, revealed its potential to successfully treat the problem of pumping management in coastal aquifers.

The approach employed in our previous work (Stratis et al. 2015) was to combine the groundwater simulation model PTC with the newly introduced constrained version of the ALOPEX stochastic optimization technique. The objective was to maximize groundwater withdrawal in the existing pumping well network while avoiding saltwater to enter a safe zone around the active wells in the region.

In the present work, although the objective of creating an optimal pumping plan for the real case aquifer of Hersonissos remains the same, we also present in detail

- The adaptation of an appropriate penalty system, which, in cooperation with the unconstrained version of ALOPEX used here (ALOPEX V), deals with the problem of controlling the advancement of saltwater front inside the aquifer,

- The creation of a safety net, namely a polygonal grid of guarding nodes, delimiting a salinization free safety area around each active pumping location,

- Several pumping scenarios, with different positions of active pumping locations and different recharging values from natural resources (rain, nearby rivers, etc.),

- The study of presenting solutions able to resolve the local community's current needs of freshwater pumping volume, by suggesting new pumping active locations.

\section{Methodology}

\section{Groundwater simulation model: PTC}

Princeton Transport Code (PTC, Babu et al. 1997) is a well-known three-dimensional groundwater flow and contaminant transport simulator that uses a combination of finite element and finite difference methods to solve the groundwater flow equation which, for the heterogeneous isotropic unconfined case, takes the form (cf. Fetter 1988)

$$
\nabla \cdot(K h \nabla h)+W=S_{y} \frac{\partial h}{\partial t}
$$


where $h$ denotes the hydraulic head, $K$ is the hydraulic conductivity (considered to be heterogeneous and isotropic), $W$ is the volumetric flux per volume unit representing sources and/or sinks of water, $S_{y}$ is the specific yield and $t$ denotes time.

PTC employs a hybrid splitting algorithm for solving the fully three-dimensional system. The domain is discretized into approximately parallel horizontal layers, within each of which a finite element discretization is employed allowing accurate representation of irregular domains. The vertical connection of the layers is represented by finite differences. This hybrid finite element and finite difference coupling provides the opportunity to divide the computations into two steps during a given time iteration (splitting algorithm). At the first step, all horizontal equations are solved while at the second step, the vertical equations which connect the layers are solved (cf. Babu et al. 1997). This model has been successfully used in several previous studies (e.g., Aivalioti and Karatzas 2006; Koukadaki et al. 2007; Dokou and Pinder 2011).

\section{Sharp interface approach}

In this work, the PTC model is used in conjunction with the sharp interface approach and the Ghyben-Herztberg approximation in order to estimate the saltwater intrusion extent. The sharp interface is a hydraulic approach, thus only the hydraulic head values on the model domain are needed to approximate the saltwater intrusion extent, as opposed to other approaches that utilize chloride or electrical conductivity measurements. The main assumption is that the mixing zone between the two immiscible fluids (fresh and saline water), that have different densities, is limited to an interface of a small finite width. The location of the sharp interface between the two fluids is determined by the difference between the hydraulic heads of the saline and freshwater and the volume of freshwater flowing towards the shoreline from inland (cf. Reilly and Goodman 1985). The location of the seawater intrusion front is approximated using the Ghyben-Herzberg relationship:

$\xi=\frac{\rho_{f}}{\rho_{s}-\rho_{f}} h_{\xi} \approx 40 h_{f}$,

where, $\xi$ is the interface depth below the sea level, $h_{f}$ the hydraulic head of the freshwater above the sea level, $\rho_{f}=$ $1000 \mathrm{~kg} / \mathrm{m}^{3}$ the density of freshwater and $\rho_{s}=$ $1025 \mathrm{~kg} / \mathrm{m}^{3}$ the density of saline water. This approach has been applied and extended by many researchers in the literature (e.g., Ababou and Al-Bitar (2004); Karterakis et al. (2007); Koukadaki et al. (2007); Mantoglou (2003); Papadopoulou et al. (2010), among many others).

\section{Study area and numerical model development}

The study area of Hersonissos aquifer is located on the north coast of Crete, $25 \mathrm{~km}$ from the city of Heraklion in Crete, Greece. The Hersonissos basin covers an area of about $18 \mathrm{~km}^{2}$, and stretches for $3.8 \mathrm{~km}$ in W-E direction and almost $4.7 \mathrm{~km}$ in $\mathrm{N}-\mathrm{S}$ direction. During the summer period water demand is high due to extensive touristic and agricultural activities, leading to significant drawdown in the area, intensifying the problem of seawater intrusion. The region of interest includes five pumping wells that are active all year long, especially during the dry period, in order to meet the irrigation needs and the increased population during the summer period due to tourism. The basin is covered mainly with karstified limestones of variable hydraulic conductivity and marls, whereas along the coastal line alluvial deposits with high permeability can be found (cf. Papadopoulou et al. 2009). The hydraulic conductivity values (see Fig. 1) used for each geologic formation were $12.96 \mathrm{~m} /$ day for limestones and dolomitic limestones, $5.2 \mathrm{~m} /$ day for bioclastic limestones, $0.15 \mathrm{~m} /$ day for marl formations, $0.6 \mathrm{~m} /$ day for clay and 430 for alluvial deposits located near the coastline (cf. Karterakis et al. 2007).

Initially, a 6-month groundwater flow simulation, representing the dry season, when saltwater intrusion is more intense, was implemented. This was followed, in the sequel, by a 6-month wet season simulation to study the aquifer's response to saltwater intrusion during conditions of increased freshwater inflow to the basin. A Dirichlet boundary condition of fixed head equal to $100 \mathrm{~m}$ was applied along the coastline to simulate the sea boundary, assuming a change in the reference level from the sea level to the bottom of the aquifer (the aquifer bottom elevation was set to zero thus the sea level was set to $100 \mathrm{~m}$ ). Various Neumann conditions were applied at the southern boundary of the region during the calibration process, to

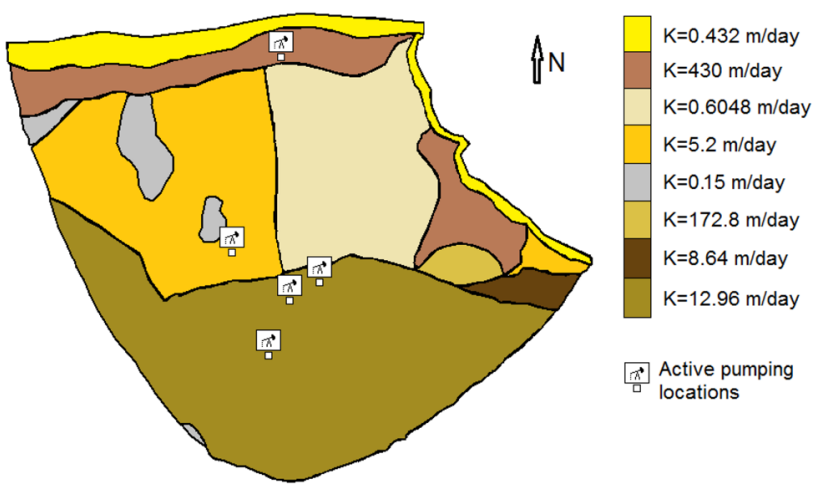

Fig. 1 Areas with different hydraulic conductivity values at the Hersonissos aquifer 


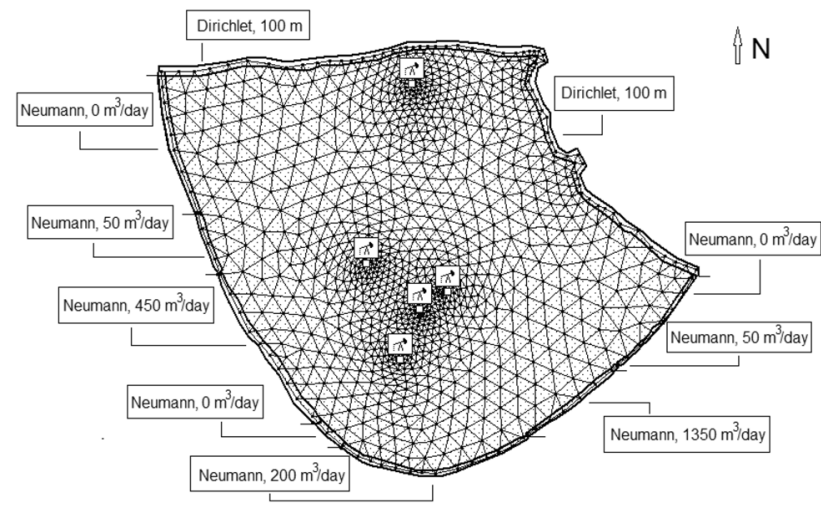

Fig. 2 Sideways water recharge values and the discretization mesh of 1984 elements and 1050 nodes, the PTC code uses to estimate the hydraulic head values inside the aquifer

simulate groundwater inflow from connecting basins and match the measured hydraulic head values at the wells (see Fig. 2).

Regarding the saltwater intrusion toe location, according to the Ghyben-Herzberg relationship, $h_{f}$ was estimated at $2.5 \mathrm{~m}$, given that the depth of the studied aquifer is about $100 \mathrm{~m}$ (based on boring log information). Thus, the contour of $100+2.5=102.5 \mathrm{~m}$ represents the hydraulic head isolevel limit below which a zone is considered intruded by saltwater.

\section{Pumping management}

To fix notation, let $M$ be the number of active wells in the region and let the vector $\mathbf{Q}$ be defined by

$\mathbf{Q}=\left(\mathbf{Q}_{\mathbf{1}}, \ldots, \mathbf{Q}_{\mathbf{M}}\right)$

where $Q_{i}$, denotes the pumping rate of the $i$ th active well with coordinates $\left(x_{i}, y_{i}\right)$, for $i=1, \ldots, M$. The objective, to maximize groundwater withdrawal while avoiding saltwater to enter a safe zone around all active wells, may then be described by the following nonlinear optimization problem (cf. Stratis et al. 2015):

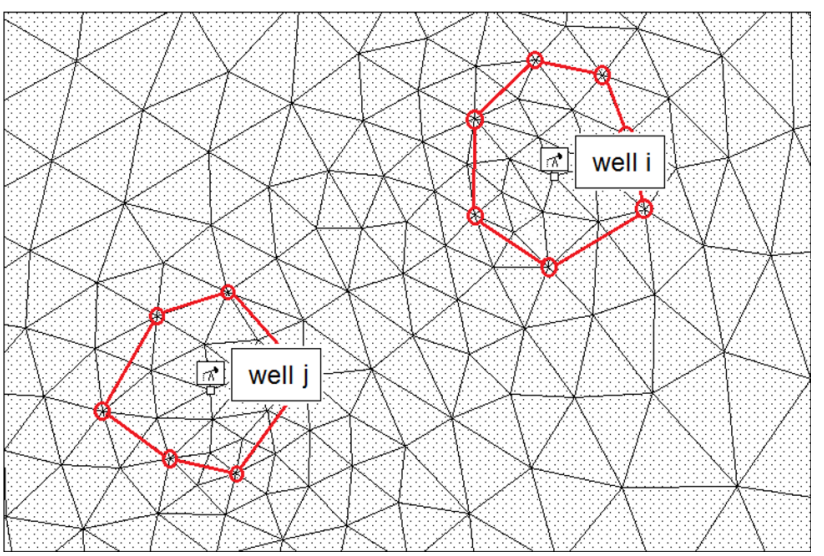

Fig. 3 Guard nodes (in red circles) around every aquifer well, set at an average distance of $d_{s}=180 \mathrm{~m}$. A polygonal area of protection is created, where the application of ALOPEX's penalties system provides an effective control on the movement of saltwater front inside the aquifer

\section{Safety strategy}

The role of the parameter $d_{s}$, defined in (4), is central in introducing a safety strategy. In this work, $d_{s}$ is considered to represent the average radius of a polygonal area of protection around each active pumping location. This area consists of a number of guarding nodes, surrounding the active pumping locations (see Fig. 3). Clearly the amplitude of its value affects the balance between the maximum volume of freshwater pumped from each active well, and at the same time, its safety from saltwater intrusion. In our present implementation, the decisive factor for the determination of $d_{s}$ value is the demand of keeping saltwater's front outside the perimeter of the safety area for all suggested ALOPEX pumping rates, while keeping the well safe from saltwater contamination even if an artificial increment of $10 \%$ is enforced in all suggested pumping rates. This requirement directly led us in determining the value of $d_{s}$ via simulations as

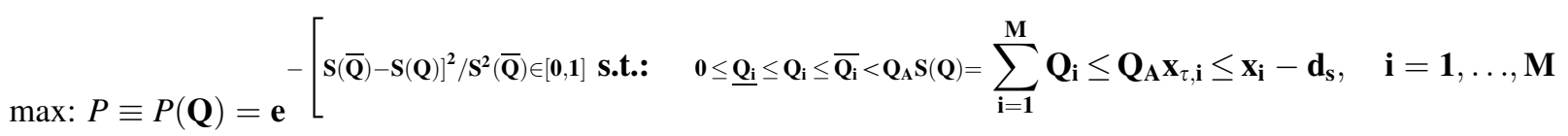

where $P$ denotes the profit (objective) function, $Q_{i}$ and $\overline{Q_{i}}$ are the minimum and maximum, respectively, pumping capabilities of the $i$ th well, $Q_{A}$ is the total recharge capabilities of the aquifer, $x_{\tau, i}$ is the $x$-coordinate of the saltwater's front in the neighborhood of the $i$ th well and $d_{s}$ is a prespecified safety distance. $d_{s}=180 \mathrm{~m}$.

We remark that the above value, although in our present implementation is kept uniform for all active wells, can be set differently for every active pumping location, accordingly to a local protection strategy. 


\section{Constrained ALOPEX for pumping management}

For the solution of the nonlinear optimization problem (4), described in the previous section, we employ ALOPEX stochastic optimization algorithm coupled with a penalty system to enforce problem's constraints. To be more specific, in each iteration step, ALOPEX updates simultaneously the values of all control variables $Q_{i}, i=1, \ldots, M$ by means of the following vector rule: with $S_{0}^{(k)}=S\left(Q_{1}^{(k-1)}, \ldots, Q_{M}^{(k-1)}\right)$, if $\tilde{S}>0$, then the value of $Q_{i}^{(k)}$ is being further rectified by

$Q_{i}^{(k)}=Q_{i}^{(k)}-(1+\delta) \tilde{S}$

for $i=1, \ldots, M$.

- In phase two, the enforcement of the toe-constraint is being achieved in two cycles. In cycle one, only the pumping rates of the active wells at risk, meaning

$\mathbf{Q}^{(\mathbf{k})}=\mathbf{Q}^{(\mathbf{k}-\mathbf{1})}+\mathbf{c}_{\mathbf{k}} \Delta \mathbf{Q}^{(\mathbf{k}-\mathbf{1})} \Delta \mathbf{P}^{(\mathbf{k}-\mathbf{1})}+\mathbf{g}^{(\mathbf{k})} \quad$ with $\Delta \mathbf{Q}^{(\mathbf{k})}=\mathbf{Q}^{(\mathbf{k})}-\mathbf{Q}^{(\mathbf{k}-\mathbf{1})} \Delta \mathbf{P}^{(\mathbf{k})}=\mathbf{P}\left(\mathbf{Q}^{(\mathbf{k})}\right)-\mathbf{P}\left(\mathbf{Q}^{(\mathbf{k}-\mathbf{1})}\right)$

where $c_{k}$ is a real parameter controlling the amplitude of the feedback term, while $\mathbf{g}^{(\mathbf{k})}$ is the noise vector, with values uniformly distributed in an appropriately chosen interval, in order to provide the necessary agitation needed to drive the process to global extrema avoiding local problems. The methodology for determining a near optimal set of values for $c_{k}$ and $\mathbf{g}^{(\mathbf{k})}$ is thoroughly discussed in Stratis et al. (2015).

In each ALOPEX iteration step all control variables $Q_{i}, i=1, \ldots, M$ are being rectified, if needed, via a twophase penalty system. Phase one refers to the enforcement of the first two constraints described in (4), and precedes PTC's implementation, while phase two refers to the enforcement of the third toe-constraint described in (4), needs the trace of the saltwater interface and, thus, follows PTC's implementation. Although the algorithms of implementing said penalty system are described in detail in Stratis et al. (2015), some key-points follows:

- In both penalty phases, the values of those $Q_{i}$ needed to be rectified, are being, ultimately, reduced or increased by a percentage, which in our implementation (as in Stratis et al. 2015) has been set to $5 \%$. This is a $5 \%$ policy, applied by the parameter $\delta=0.05$.

- In phase one, the current pumping rate $Q_{i}^{(k)}$ of the $i$ th well, obtained in (6), is being rectified in case it violates the local maximum, the local minimum or the global maximum pumping rate constraints. Namely, in case $Q_{i}^{(k)}>\bar{Q}_{i}$ or $Q_{i}^{(k)}<Q_{i}$, the value of $Q_{i}^{(k)}$ is being rectified by

$Q_{i}^{(k)}=(1-\delta) \bar{Q}_{i}$ or $Q_{i}^{(k)}=(1+\delta) \underline{Q}_{i}$

for $i=1, \ldots, M$. And furthermore, having defined the quantities

$$
\begin{aligned}
S_{i-1}^{(k)} & :=\sum_{j=1}^{i-1} Q_{j}^{(k)}+\sum_{j=i}^{M} Q_{j}^{(k-1)} \text { and } \\
\tilde{S} & :=S_{i-1}^{(k)}+\Delta Q_{i}^{(k)}-\bar{Q}_{A}
\end{aligned}
$$

$x_{\tau, i}>x_{i}-d_{s}$, are being rectified by the penalty equation

$Q_{i}^{(k)}=(1-\delta) Q_{i}^{(k)}$

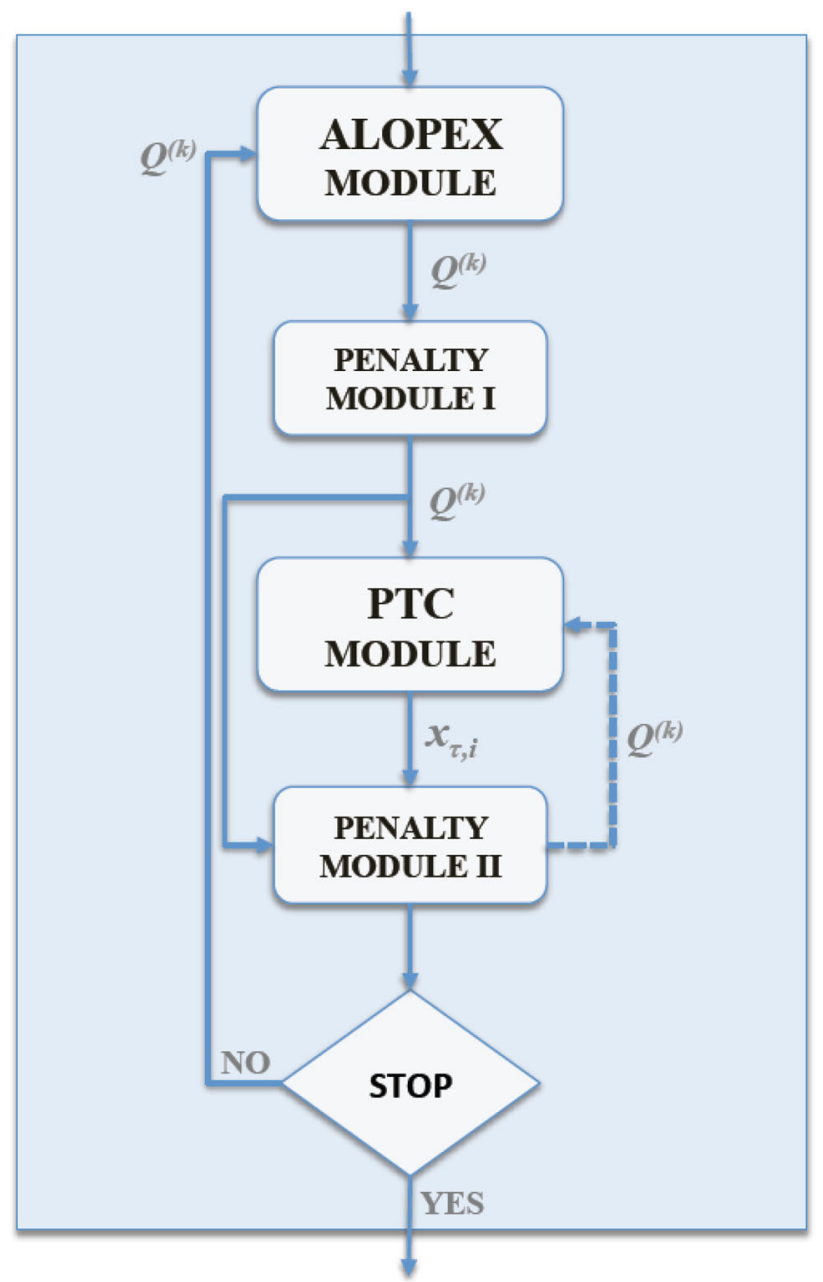

Fig. 4 Flow chart of the ALOPEX/PTC pumping management methodology 

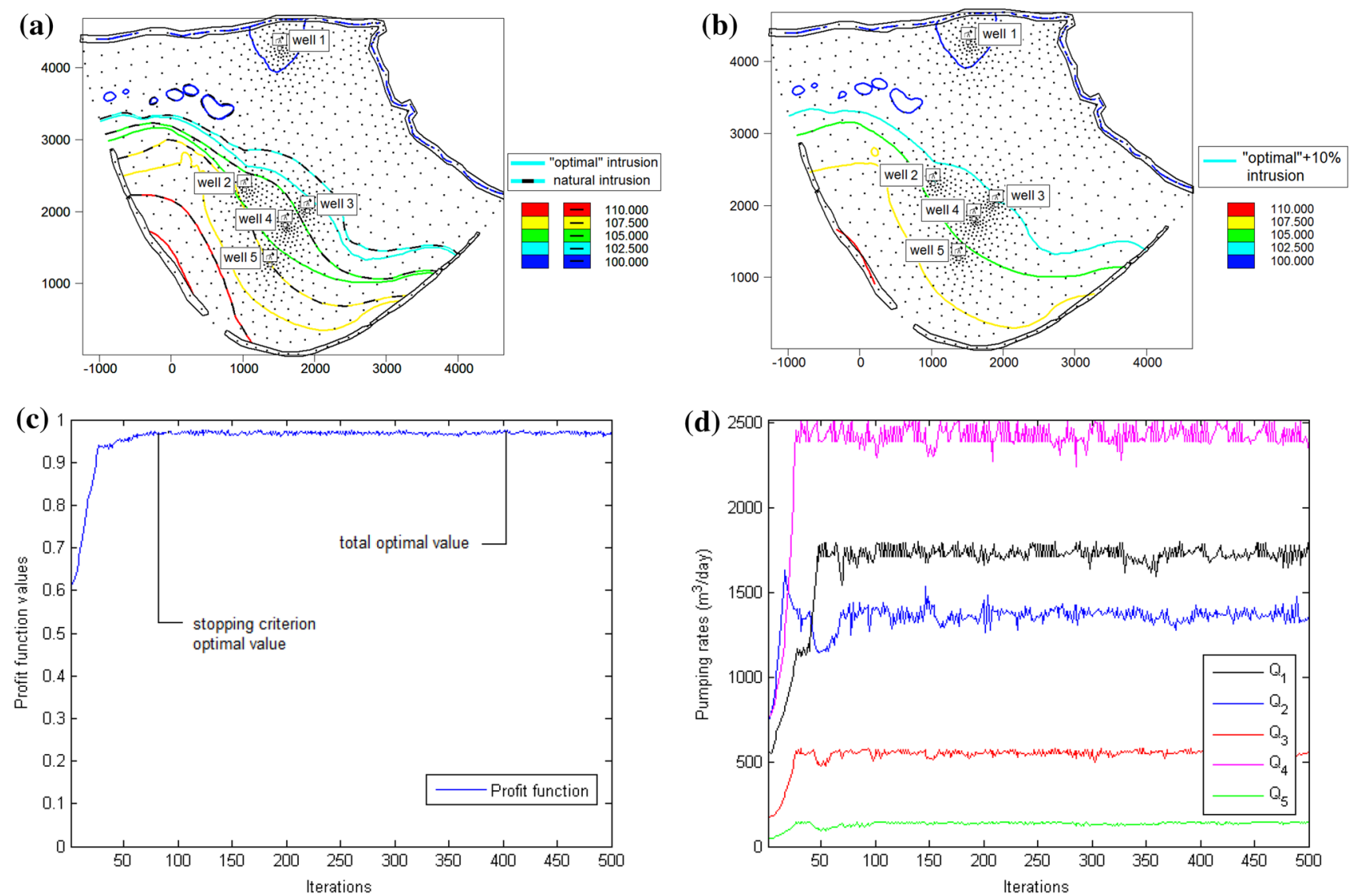

Fig. 5 Profile DRY_5: ALOPEX/PTC performance for the Dry case scenario with five (5) active pumping locations in a typical run of 500 iterations. a Hydraulic head isolevel curves using the optimal pumping rates. The countour line at $102.5 \mathrm{~m}$ denotes the saltwater interface position. Wells No 2-5 remain safe from saltwater intrusion. b Hydraulic head isolevel curves using the optimal pumping

for $i=1, \ldots, M$. Then, in cycle two, if the previous local rectification did not manage to protect the wells in danger, a global rectification is applied during which the penalty presented in equation (10) is being enforced on all aquifer wells.

- In order to create an effective stopping criterion for the optimization procedure, we use a combination of the standard deviation $\sigma_{\hat{k}}$ of the objective function's values in the last $\hat{k}$ iterations (in the present work $\hat{k}=20$ ) and the differential of the objective function's mean value $\mu_{\hat{k}}$, in a window of the last $2 \hat{k}$ iterations. We define the windowed mean value $\mu_{\hat{k}}$ and standard deviation $\sigma_{\hat{k}}$ as

$\mu_{\hat{k}}=\frac{1}{\hat{k}} \sum_{i=k-\hat{k}}^{k} P\left(\mathbf{Q}^{(\mathbf{i})}\right) \quad$ and $\sigma_{\hat{\mathbf{k}}}=\sqrt{\frac{\mathbf{1}}{\hat{\mathbf{k}}} \sum_{\mathbf{i}=\mathbf{k}-\hat{\mathbf{k}}}^{\mathbf{k}}\left(\mathbf{P}\left(\mathbf{Q}^{(\mathbf{i})}\right)-\mu_{\hat{\mathbf{k}}}\right)^{\mathbf{2}}}$

ratesincreased by $10 \%$. Wells No 2-5 still remain safe from saltwater intrusion.Saltwater front violates the safe area surrounding well No. 3although it remains safe. The countour line at $102.5 \mathrm{~m}$ denotes the saltwaterinterface position. $\mathbf{c}$ Values of $\mathrm{P}\left(\mathbf{Q}^{(k)}\right)$ during a cycle of $k=$ 500 iterations, remainingclose to an optimal value after almost 80 iterations. Pumping rates $Q_{i}$ during a cycle of $k=500$ iterations

where $k$ is the current iteration, with $k-2 \hat{k}>0$. Then, assuming that no constraint is being violated, the satisfaction of the following criterion

$$
\left(\sigma_{\hat{k}}<\varepsilon_{1}\right) \wedge\left(\left|\mu_{\hat{k}}-\mu_{2 \hat{k}}\right|<\varepsilon_{2}\right)
$$

for positive small tolerances $\varepsilon_{1}$ and $\varepsilon_{2}$ (in the present work both set equal to $10^{-2}$ ), effectively terminates the optimization procedure.

Finally, in Fig. 4 that follows, the ALOPEX/PTC pumping management methodology, described in the above paragraphs, is being depicted via the flow chart of the whole process.

\section{Numerical simulations}

In this section we include the results from characteristic numerical simulations performed for the freshwater aquifer located at the Municipality of Hersonissos, $25 \mathrm{~km}$ east of Heraklion, at the Greek island of Crete. 
Table 1 Pumping Capabilities $\left(\mathrm{m}^{3} /\right.$ days $)$ of Active Locations

\begin{tabular}{lrrrrr}
\hline$i$ & \multicolumn{1}{l}{1} & \multicolumn{1}{l}{ 2 } & \multicolumn{1}{l}{4} & \multicolumn{1}{l}{5} \\
\hline $\bar{Q}_{i}$ & 1800.00 & 2520.00 & 576.00 & 2520.00 & 146.00 \\
$\underline{Q}_{i}$ & 540.00 & 756.00 & 172.80 & 756.00 & 43.80 \\
\hline
\end{tabular}

Table 2 ALOPEX/PTC performance: Profile DRY_5

\begin{tabular}{lll}
\hline $\begin{array}{l}\text { Problem } \\
\text { parameters }\end{array}$ & $\begin{array}{l}\text { Total optimal } \\
\text { values }\end{array}$ & $\begin{array}{l}\text { Stopping criterion } \\
\text { optimal values }\end{array}$ \\
\hline$k$ (\# iter.) & 404 & 79 \\
$P\left(\mathbf{Q}^{(\mathbf{k})}\right)$ & 0.9756 & 0.97153 \\
$Q_{1}^{(k)}$ & 1787.02 & 1735.11 \\
$Q_{2}^{(k)}$ & 1368.66 & 1340.61 \\
$Q_{3}^{(k)}$ & 560.20 & 561.66 \\
$Q_{4}^{(k)}$ & 2519.43 & 2515.91 \\
$Q_{5}^{(k)}$ & 138.09 & 123.45 \\
$S\left(\mathbf{Q}^{(\mathbf{k})}\right)$ & 6373.40 & 6276.74 \\
$t_{k}$ & 378.5125 & 74.0161 \\
\hline
\end{tabular}

To characterize the simulation profiles included, recall the main governing flow equation from (1) and let the volumetric flux $W$ satisfy

$$
W=N-Q
$$

where $N$ denotes the recharge rate distributed over the surface of the aquifer and $Q$ denotes the discharge rate distributed over the active pumping area. Then, the simulations included refer to a dry case scenario as well as to a wet case scenario characterized by

- Dry Case $N=0 \mathrm{~mm} /$ year, while the sideways (subsurface) recharge, characterized by the Neumann boundary conditions, is as defined in Fig. 2,

- Wet Case $N=500 \mathrm{~mm} /$ year with percentage of infiltration set at $30 \%$, while the sideways recharge is as described in Fig. 2 increased by $20 \%$.

Both case scenarios consider five active public pumping locations, the coordinates of which (see Fig. 2) have been assigned via a geographical information system. From the five active wells the top one, located close to the north coastline of the aquifer (see Fig. 5a), is always flooded by seawater, independently of the pumping activities in the region. This is due to the fact that the natural saltwater intrusion, namely the hydraulic head isolevel at $102.5 \mathrm{~m}$ when $\mathbf{Q}=\mathbf{0}$ (the thin light-blue contour line included in all figures that follow), is far beyond the well's location. The water extracted from this location is always unsuitable for human consumption or land irrigation and, therefore, may as well considered to be inactive. Nevertheless, to show
Table 3 ALOPEX/PTC performance: Profile DRY_4

\begin{tabular}{lll}
\hline $\begin{array}{l}\text { Problem } \\
\text { parameters }\end{array}$ & $\begin{array}{l}\text { Total optimal } \\
\text { values }\end{array}$ & $\begin{array}{l}\text { Stopping criterion } \\
\text { optimal values }\end{array}$ \\
\hline$k$ (\# iter.) & 331 & 64 \\
$P\left(\mathbf{Q}^{(\mathbf{k})}\right)$ & 0.96042 & 0.95591 \\
$Q_{1}^{(k)}$ & 0.00 & 0.00 \\
$Q_{2}^{(k)}$ & 1392.37 & 1395.91 \\
$Q_{3}^{(k)}$ & 570.67 & 547.20 \\
$Q_{4}^{(k)}$ & 2513.18 & 2456.94 \\
$Q_{5}^{(k)}$ & 127.87 & 138.46 \\
$S\left(\mathbf{Q}^{(\mathbf{k})}\right)$ & 4604.09 & 4538.51 \\
$t_{k}$ & 304.6019 & 58.8958 \\
\hline
\end{tabular}

Table 4 ALOPEX/PTC performance: Profile WET_5

\begin{tabular}{lll}
\hline $\begin{array}{l}\text { Problem } \\
\text { parameters }\end{array}$ & $\begin{array}{l}\text { Total optimal } \\
\text { values }\end{array}$ & $\begin{array}{l}\text { Stopping criterion } \\
\text { optimal values }\end{array}$ \\
\hline$v(\#$ iter. $)$ & 198 & 63 \\
$P\left(\mathbf{Q}^{(\mathbf{k})}\right)$ & 0.99999 & 0.99654 \\
$Q_{1}^{(k)}$ & 1777.16 & 1518.21 \\
$Q_{2}^{(k)}$ & 2514.42 & 2426.24 \\
$Q_{3}^{(k)}$ & 545.27 & 545.98 \\
$Q_{4}^{(k)}$ & 2511.35 & 2502.93 \\
$Q_{5}^{(k)}$ & 136.80 & 123.41 \\
$S\left(\mathbf{Q}^{(\mathbf{k})}\right)$ & 7485.00 & 7116.77 \\
$t_{k}$ & 178.7071 & 56.8614 \\
\hline
\end{tabular}

that the proposed ALOPEX/PTC methodology is not affected by the active or inactive status of this location, the results reported include both statuses.

In Table 1 we have included the maximum $\bar{Q}_{i}$ pumping capabilities of all five active locations, while the corresponding minimum ones have been set to satisfy $\underline{Q}_{i}=0.3 * \bar{Q}_{i}$. Finally, we note that in all numerical simulations the pumping rates $Q_{i}, i=1, \ldots, M$ are considered to be numbered in a top-to-bottom fashion, namely $y_{1} \geq \ldots \geq y_{M}$.

\section{Profile DRY_5: dry case, five (5) active pumping locations}

Profile DRY_5 corresponds to a dry, summer case ( $N=0 \mathrm{~mm} /$ year) scenario, with the north-top well being active (pumping, of course, saline water). All results from the ALOPEX/PTC pumping management performance, 

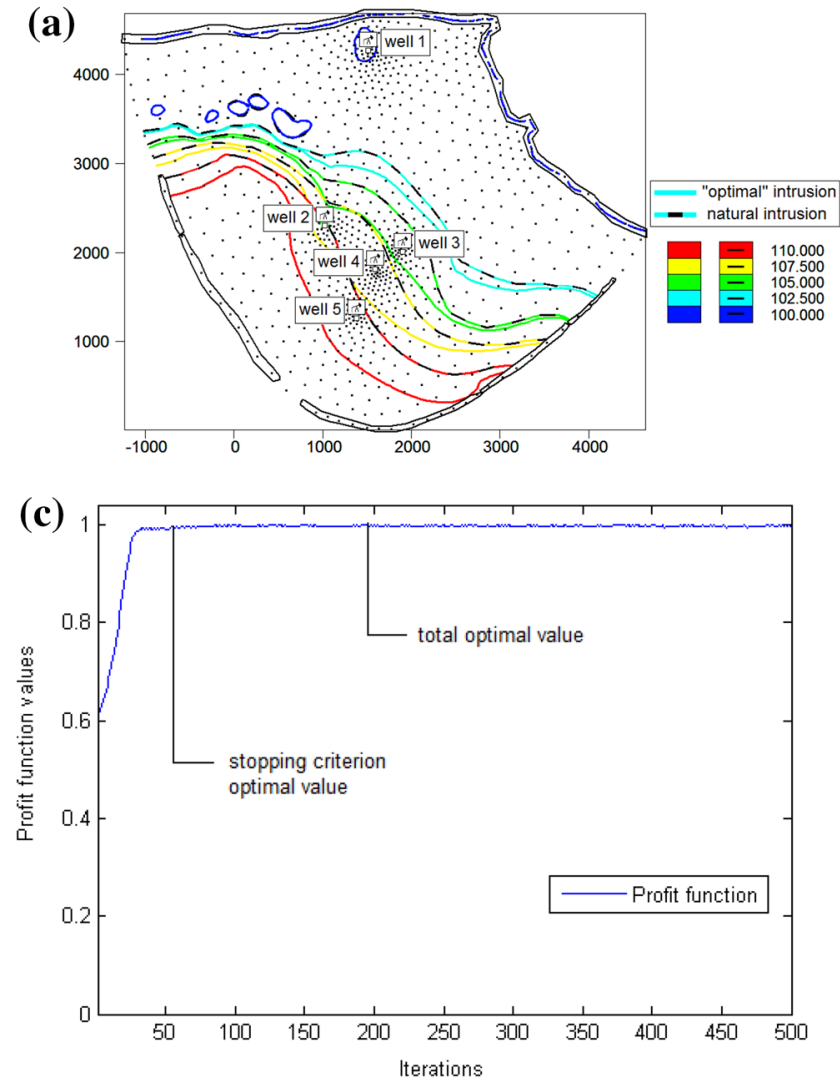

Fig. 6 Profile WET_5: ALOPEX/PTC performance for the Wet case scenario with five (5) active pumping locations in a typical run of 500 iterations. a Hydraulic head isolevel curves using the optimal pumping rates.The countour line at $102.5 \mathrm{~m}$ denotes the saltwater interface position.Wells No $2-5$ are kept safe from saltwater intrusion. b Hydraulic head isolevel curves using the optimal

during a typical cycle of 500 iterations, are summarized in Table 2 (where $t_{k}$ is the computational time of the ALOPEX/PTC algorithm until $k$ th iteration, in secs) and Fig. 5.

Inspecting now Fig. 5a, it may be easily verified that all pumping locations, except naturally the top one, remain safe from saltwater intrusion, since the saltwater interface was kept (contour line at $h=102.5 \mathrm{~m}$ ) at a distance of at least $d_{s}=180 \mathrm{~m}$ away from all protected active locations. It is also significant that, as Fig. 5b suggests, increments of $10 \%$ on all optimal pumping rates $Q_{i}$ (reported in Table 2) do not pose any threat on the integrity of the protected active pumping locations, due to the appropriate value of the safety distance $d_{s}$, described earlier at Sect. 2.5. As it pertains now to the ALOPEX performance, notice that (see Fig. 5c) the algorithm drives the objective function to a narrow neighborhood of its constrained maximum after almost 80 iterations and remains close to it, for the rest of the process, within relatively small amplitude fluctuations. Similar behavior may be observed, in Fig. 5d, for the process's control variables $Q_{i}$. The overall running time of the optimization procedure equals to $t_{500}=468.4561 \mathrm{~s}$,
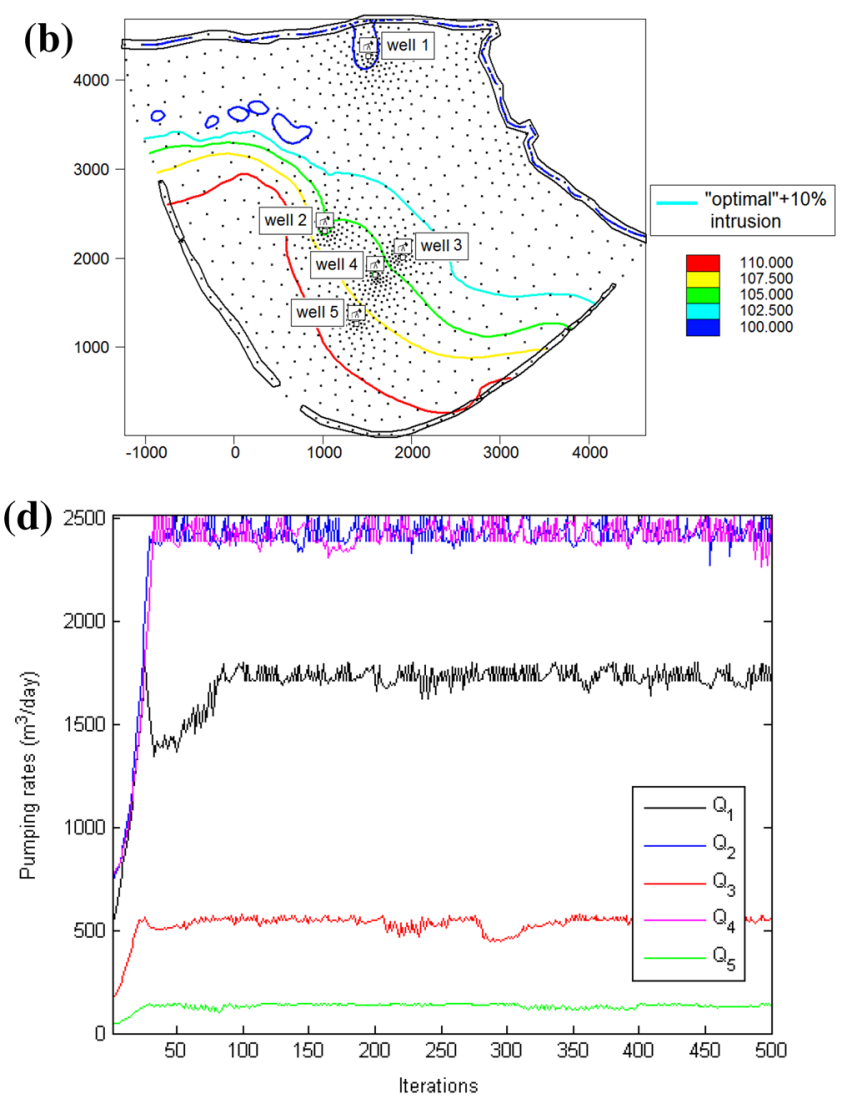

pumping ratesincreased by $10 \%$. The countour line at $102.5 \mathrm{~m}$ denotes the saltwaterinterface position. $\mathbf{c}$ Values of $\mathrm{P}\left(\mathbf{Q}^{(k)}\right)$ during a cycle of $k=500$ iterations. TheProfit function receives almost its maximum value, after a few iterations. d Pumping rates $Q_{i}$ during a cycle of $k=500$ iterations

with an average time per iteration equal to $0.9369 \mathrm{~s}$. We point out that the computationally intense part of this procedure is the execution of the PTC module. Therefore the total computational cost mainly depends on the number of PTC executions, which is closely related to the number of times the penalty system is forced to rectify the current suggested pumping values.

\section{Profile DRY_4: dry case, four (4) active pumping locations}

Let us, now, consider the case of four pumping active locations. Namely, well No. 1, the one closest to the coastline, is deactivated to ensure that only freshwater is pumped from the active wells. The results of a typical run of 500 iterations are presented in Table 3. Figures are omitted as they are practically identical to the ones reported in the previous case indicating the insignificant role of well No. 1 in the optimization process. This fact is being further backed up by the results included in Table 3 . 

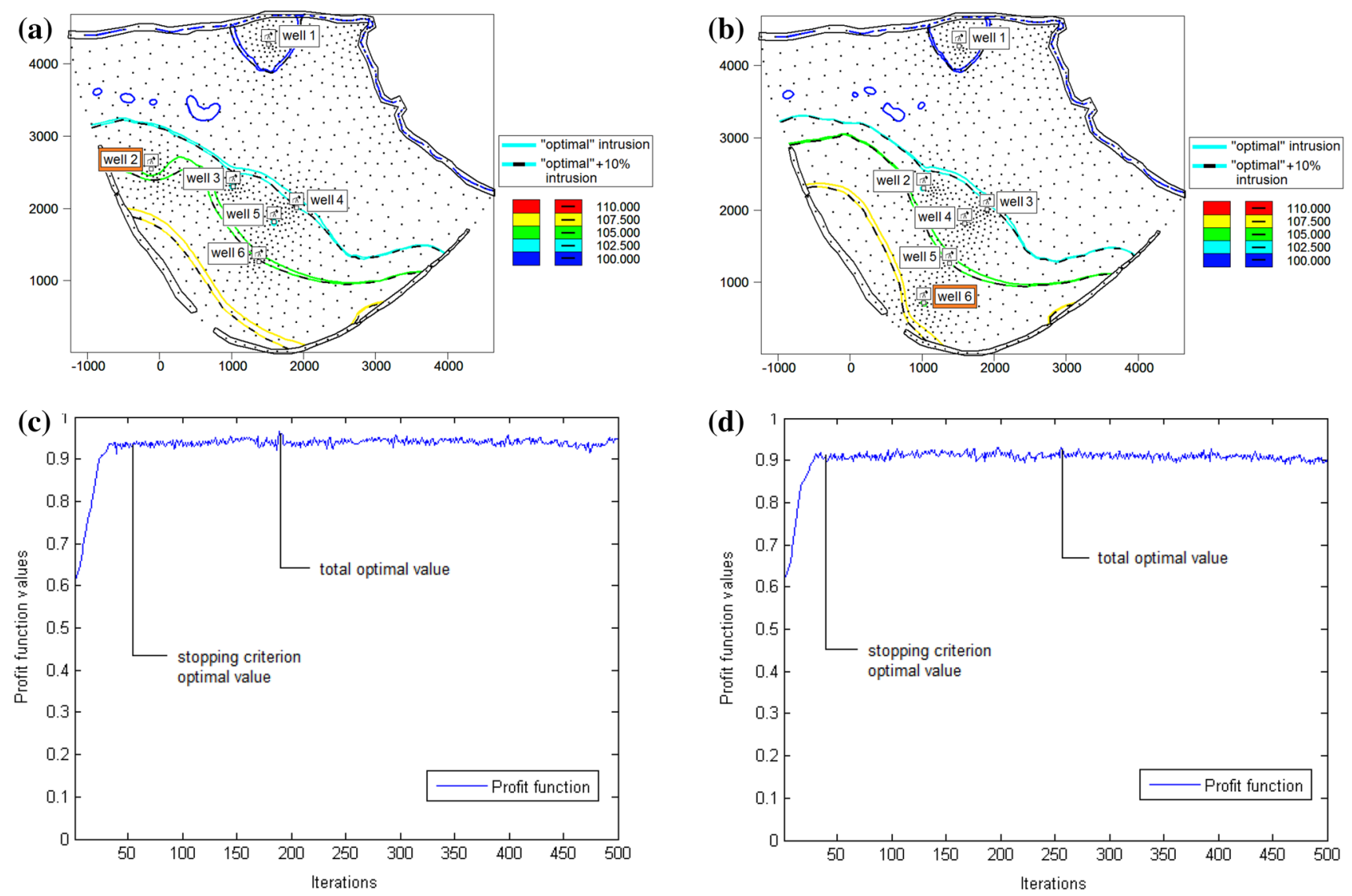

Fig. 7 Profile DRY_6: ALOPEX/PTC performance for the Dry case scenario with six (6) active pumping locations in a typical run of 500 iterations. a Case DRY_6A: Hydraulic head isolevel curves using the optimaland the optimal increased by $10 \%$ pumping rates. The countour lineat $102.5 \mathrm{~m}$ denotes the saltwater interface position. Saltwater frontviolates the safe area surrounding well No. 4 although

Indeed one may readily verify that, omitting the values associated to well No. 1 from Table 2, the rest of the reported results remain practically identical to the results included in Table 3. Therefore, the presence or absence of well No. 1 from the optimization process does not affect the optimal values of the rest of the active locations. Nevertheless, well No. 1 is being kept active in our simulations for literature compatibility reasons.

\section{Profile WET_5: wet case, five (5) active pumping locations}

All results, pertaining to the wet (winter) case $(N=500)$ scenario, from the ALOPEX/PTC pumping management performance, during a typical cycle of 500 iterations, are summarized in Table 4 and Fig. 6 that follow. By inspection only of the reported results one may easily verify that this is an untroubled case in the sense that the active pumping locations may perform at maximum pumping rates without any threat from saltwater intrusion.

it remains safe. b Case DRY_6B: Hydraulic head isolevel curves using the optimaland the optimal increased by $10 \%$ pumping rates. The countour lineat $102.5 \mathrm{~m}$ denotes the saltwater interface. Wells No. 2-6 are kept safefrom saltwater intrusion. c Case DRY_6A: Values of $\mathrm{P}\left(\mathbf{Q}^{(k)}\right)$ during a cycle of $k=500$ iterations. d Case DRY_6B: Values of $\mathrm{P}\left(\mathbf{Q}^{(k)}\right)$ during a cycle of $k=500$ iterations

Indeed, as both Fig. 6a, b suggest, all pumping locations, except naturally the top one, remain safe from saltwater intrusion, since the saltwater interface (contour line at $h=102.5 \mathrm{~m}$ ) is not even close to the safety distance of $d_{s}=180 \mathrm{~m}$ from all protected active locations. ALOPEX drives in less than 50 iterations (see Fig. 6c) the objective function to its global maximum and remains close to it, for the rest of the process, within very small amplitude fluctuations. Similarly, inspecting Fig. 6d, it can be noticed that all control variables $Q_{i}$ reach within a few iterations maximum performance.

\section{Profile DRY_6: dry case, six (6) active pumping locations}

The final case study we report in this work, refers to the scenario of increasing the total pumping rate during the dry season (summer) by adding a new hypothetical active pumping location of adequately large pumping capability.

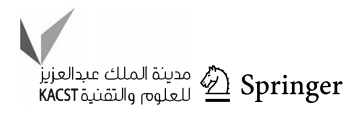


Table 5 ALOPEX/PTC performance: Profile DRY_6A

\begin{tabular}{lll}
\hline $\begin{array}{l}\text { Problem } \\
\text { parameters }\end{array}$ & $\begin{array}{l}\text { Total optimal } \\
\text { values }\end{array}$ & $\begin{array}{l}\text { Stopping criterion } \\
\text { optimal values }\end{array}$ \\
\hline$k(\#$ iter. $)$ & 189 & 58 \\
$P\left(\mathbf{Q}^{(\mathbf{k})}\right)$ & 0.96473 & 0.9416 \\
$Q_{1}^{(k)}$ & 1710.00 & 1790.87 \\
$Q_{2}^{(k)}$ & 2499.29 & 2111.83 \\
$Q_{3}^{(k)}$ & 1099.91 & 1016.55 \\
$Q_{4}^{(k)}$ & 227.50 & 286.30 \\
$Q_{5}^{(k)}$ & 2504.28 & 2247.74 \\
$Q_{6}^{(k)}$ & 114.34 & 140.54 \\
$S\left(\mathbf{Q}^{(\mathbf{k})}\right)$ & 8155.32 & 7593.83 \\
$t_{k}$ & 337.5716 & 103.5934 \\
\hline
\end{tabular}

Table 6 ALOPEX/PTC performance: Profile DRY_6B

\begin{tabular}{lll}
\hline $\begin{array}{l}\text { Problem } \\
\text { parameters }\end{array}$ & $\begin{array}{l}\text { Total optimal } \\
\text { values }\end{array}$ & $\begin{array}{l}\text { Stopping criterion } \\
\text { optimal values }\end{array}$ \\
\hline$k(\#$ iter. $)$ & 256 & 35 \\
$P\left(\mathbf{Q}^{(\mathbf{k})}\right)$ & 0.93066 & 0.91743 \\
$Q_{1}^{(k)}$ & 1710.00 & 1710.00 \\
$Q_{2}^{(k)}$ & 1263.83 & 1303.97 \\
$Q_{3}^{(k)}$ & 181.44 & 194.16 \\
$Q_{4}^{(k)}$ & 1728.71 & 1805.58 \\
$Q_{5}^{(k)}$ & 87.26 & 81.42 \\
$Q_{6}^{(k)}$ & 2393.37 & 2012.97 \\
$S\left(\mathbf{Q}^{(\mathbf{k})}\right)$ & 7364.61 & 7108.10 \\
$t_{k}$ & 500.9508 & 68.4894 \\
\hline
\end{tabular}

Two different locations, for the sixth new active well, were chosen in a particular aquifer sector that does not significantly affect the saltwater front advancement.

These new positions are marked by Well 2 and Well 6 on Fig. 7a, b, respectively, and their corresponding maximum and minimum pumping rates were set to $\left(\bar{Q}_{2}, Q_{2}\right)=$ $(2500,750) \mathrm{m}^{3} /$ day and $\left(\bar{Q}_{6}, \underline{Q}_{6}\right)=(2500,750) \mathrm{m}^{3} /$ day. All simulation results obtained for this case are summarized in Tables 5, 6 and in Fig. 7.

Inspecting, now, Tables 5 and 6 , it can be readily verified that both case scenarios resulted in significantly increased total volume of optimal pumping rates. The differences observed between the total volume of the optimal pumping rates, as well as the distribution of the pumping volume among the active locations in both case scenarios, suggest that the location of the extra artificial well significantly affects the final optimal pumping setup.
In conclusion, the above simulation results suggest that the Hersonissos aquifer might be able to deliver increased pumping volume capability by following the described strategy. Further investigation in this direction is required.

Finally, we report that all experiments were conducted on an Intel quad-core i7, 3.4 Mhz PC, with 8 Gb DDR3 RAM, using PTC and MATLAB environments.

\section{Conclusion}

In this study, we combine the PTC groundwater simulation model with the newly introduced constrained version of the ALOPEX stochastic optimization technique, in an attempt to maximize groundwater withdrawal in the existing pumping well network without risking saltwater contamination of the active pumping locations. For this, we introduce a nodal safety strategy that controls saltwater front's advancement inside the aquifer and prohibits saltwater intruding a safety zone around the active pumping locations in the region. The results, for both dry and wet case scenarios considered, revealed that the ALOPEX stochastic optimization method cooperates effectively with PTC, proving a new simple and effective tool for studying saltwater intrusion in coastal aquifers. We strongly believe that the reported results justify and encourage further investigation on the performance of the method.

Acknowledgments The present research work has been co-financed by the European Union (European Social Fund ESF) and Greek national funds through the Operational Program Education and Lifelong Learning of the National Strategic Reference Framework (NSRF)—Research Funding Program: THALES (Grant Number: MIS-379416). Investing in knowledge society through the European Social Fund.

Open Access This article is distributed under the terms of the Creative Commons Attribution 4.0 International License (http:// creativecommons.org/licenses/by/4.0/), which permits unrestricted use, distribution, and reproduction in any medium, provided you give appropriate credit to the original author(s) and the source, provide a link to the Creative Commons license, and indicate if changes were made.

\section{References}

Ababou R, Al-Bitar A (2004) Salt water intrusion with heterogeneity and uncertainty: mathematical modeling and analyses. Dev Water Sci 55:1559-1571

Aivalioti M, Karatzas G (2006) Modeling the flow and leachate transport in the vadose and saturated Zone-a field application. Env Model Assess 11(1):81-87

Alimohammadi S, AfsharUnit A (2005) Response matrix coefficients development; ANN Approach. In: Proceedings of the 5th WSEAS/IASME International Conference on Systems Theory and Scientific Computation. Malta, pp 17-25 
Babu D, Pinder G, Niemi A, Ahlfeld D, Stothoff S (1997) Chemical transport by three-dimensional groundwater flows. Princeton University, USA (84-WR-3)

Cai X, McKinney DC, Lasdon LS (2001) Solving non-linear water management models using a combined genetic algorithm and linear programming approach. Adv Water Resour 24:667676

Dhar A, Datta B (2009) Saltwater intrusion management of coastal aquifers, I: linked simulation-optimization. J Hydrol Eng 14(12): 12631272

Dokou Z, Karatzas G (2012) Saltwater intrusion estimation in a karstified coastal system using density-dependent modelling and comparison with the sharp-interface approach. Hydrol Sci J 57(5):985-999

Dokou Z, Pinder G (2011) Extension and field application of an integrated DNAPL source identification algorithm that utilizes stochastic modeling and a Kalman filter. J Hydrol 398(3-4):277-291

Fetter CW (1988) Applied hydrogeology. Merrill Publishing Company, Chicago

Gorelick SM, Voss CI, Gill PE, Murray W, Saunders MA, Wright MH (1984) Aquifer reclamation design: the use of contaminant transport simulation combined with non-linear programming. Water Resour Res 20(4):415427

Guvanase V, Wade S, Barcelo M (2000) Simulation of regional ground water flow and salt water intrusion in Hernando County, Florida. Ground Water 38(5):772-783

Harth E, Tzanakou E (1974) Alopex: a stochastic method for determining visual receptive fields. Vision Res 14(12):1475-1482

Karatzas G, Dokou Z (2015) Managing the saltwater intrusion phenomenon in the coastal aquifer of Malia. Hydrogeol J. doi:10. 1007/s10040-015-1286-6

Karterakis S, Karatzas G, Nikolos I, Papadopoulou M (2007) Application of linear programming and differential evolutionary optimization methodologies for the solution of coastal subsurface water management problems subject to environmental criteria. J Hydrol 342(3-4):270-282

Ketabchi H, Ataie-Ashtiani B (2015) Review: Coastal groundwater optimizationGadvances, challenges, and practical solutions. Hydrol J 23(6):1129-1154

Koukadaki M, Karatzas G, Papadopoulou M, Vafidis A (2007) Identification of the saline zone in a coastal aquifer using electrical tomography data and simulation. Water Resour Manage 21(11):1881-1898

Kourakos G, Mantoglou A (2011) Simulation and multi-objective management of coastal aquifers in semi-arid regions. Water Resour Manage 25:10631074

Llopis-Albert C, Pulido-Velazquez D (2014) Discussion about the validity of sharp-interface models to deal with seawater intrusion in coastal aquifers. Hydrol Proc 28(10):36423654

Mantoglou A (2003) Pumping management of coastal aquifers using analytical models of saltwater intrusion. Water Resour Res 39(12):1335. doi:10.1029/2002WR0011891

Mantoglou A, Papantoniou M (2008) Optimal design of pumping networks in coastal aquifers using sharp interface models. J Hydrol 361:52-63
Mantoglou A, Papantoniou M, Giannoulopoulos P (2004) Management of coastal aquifers based on nonlinear optimization and evolutionary algorithms. J Hydrol 297(1-4):209-228

Ospina J, Guarin N, Velez M (2006) Analytical solutions for confined aquifers with non constant pumping using Computer Algebra. In: Proceedings of the 2006 IASME/WSEAS International Conference on Water Resources, Hydraulics and Hydrology. Chalkida, Greece, pp 7-12

Papadopoulou M, Varouchakis E, Karatzas G (2009) Simulation of complex aquifer behaviour using numerical and geostatistical methodologies. Desalination 237:42-53

Papadopoulou M, Varouchakis E, Karatzas G (2010) Terrain Discontinuity effects in the regional flow of a complex karstified aquifer. Environ Model Assess 15(5):319-328

Reilly T, Goodman A (1985) Quantitative-analysis of saltwater freshwater relationships in groundwater systems-a historical-perspective. J Hydrol 80(1-2):125-160

Reinelt P (2005) Seawater intrusion policy analysis with a numerical spatially heterogeneous dynamic optimization model. Water Resour Res 41(5):112

Shamir U, Bear J, Gamliel A (1984) Optimal annual operation of a coastal aquifer. Water Resour Res 20:435444

Sreekanth J, Datta B (2015) Review: simulation-optimization models for the management and monitoring of coastal aquifers. Hydrol $\mathrm{J}$ 23(6):1155-1166

Strack ODL (1989) Groundwater mechanics. Prentice Hall, Upper Saddle River

Stratis P, Dokou Z, Karatzas G, Papadopoulou E, Saridakis Y (2015) Stochastic optimization and numerical simulation for pumping management of the Hersonissos Freshwater Coastal Aquifer in Crete. In: Proceedings of INASE/CSCC-WHH 2015, Recent Advances in Environmental and Earth Sciences and Economics. Zakynthos, pp 329-334

Stratis P, Karatzas G, Papadopoulou E, Zakynthinaki M, Saridakis Y (2015) Stochastic optimization for an analytical model of saltwater intrusion in coastal aquifers (PLOS One submitted)

Uddameri V, Kuchanur ZM (2007) Simulation-optimization approach to assess groundwater availability in Refugio County, TX. Environ Geol 51:921929

Voudouris K, Mandilaras D, Antonakos A (2004) Methods to define the a real distribution of the salt intrusion: examples from South Greece. In: Aragus R, Custodio A, Manzano C (eds), vol. 18. SWIM. Cartagena, Spain

Werner AD, Bakker M, Post VEA, Vandenbohede A, Lu C, AtaieAshtiani B, Simmons CT, Barry A (2013) Seawater intrusion processes, investigation, and management: Recent advances and future challenges. Adv Water Resour 51:3-26

Willis R, Finney BA (1988) Planning model for optimal control of saltwater intrusion. J Water Res Plan Manag 114(2):163-178

Yeh WW (2015) Review: optimization methods for groundwater modeling and management. Hydrol J 23(6):1051-1065

Zakynthinaki M, Saridakis Y (2003) Stochastic optimization for a tiptilt adaptive correcting system. Comp Phys Commun 150(3):274 